\title{
SEA-LEVEL EFFECT ON ANNUAL CYCLIC BEACH MORPHOLOGY IN SWASH ZONE AT HASAKI COAST
}

\author{
Masayuki Banno, Port and Airport Research Institute, banno-m@pari.go.jp \\ Yoshiaki Kuriyama, Port and Airport Research Institute, kuriyama@pari.go.jp
}

\begin{abstract}
INTRODUCTION
Coastal risk assessment and adaptation to sea level rise depend on the accurate knowledge of the beach response to sea level regime on multi-time scale. For the long-term beach response, Bruun (1962) suggested that the equilibrium beach profile would move to new equilibrium profile in response to a rising sea level. In this concept called as Bruun rule, the upper part of the beach profile is eroded due to the sea level rise, resulting in the shoreline retreat. It is widely used for the future shoreline prediction. However, the Bruun rule predicts just only the final beach state with a constant wave impinging for an infinite period after sea level rise. On the other hand, simultaneous function of wave and sea level is more important on interannual to decadal-scale beach response. El niño in 2015 and 2016 increased wave energy and sea level, corresponding to large beach erosion across the US west coast (Barnard et al., 2017). Sea level influences the response sensitivity to the wave forcing as a subordinate factor on the morphological change. High water level anomalies made the beach more eroded even if the wave condition was equal. Beach morphology in the swash zone often changes on a 1-year cycle due to seasonal wave conditions. The effect of sea level on the annual cyclic beach morphology in swash zone is still unclear because long-term beach observation data required for the analysis are difficult to obtain. In this study, we investigated the simultaneous effects of the wave and sea level on annual cyclic beach morphology in the swash zone with spectrum analysis for 25-year Hasaki beach observation data.
\end{abstract}

\section{DATA DESCRIPTION}

Beach profiles were measured every workday for the 25year period from 1986 to 2010 at the Hasaki coast in Japan, facing the Pacific Ocean. We used the daily changes in cross-shore contour positions between $-1.0 \mathrm{~m}$ and $2.0 \mathrm{~m}$ from D.L. for the analysis. The high, mean and low water level on the coast are $1.25 \mathrm{~m}, 0.65 \mathrm{~m}$ and $-0.2 \mathrm{~m}$, respectively. The cross-shore contour positions of H.W.L and M.W.L. were shown in Figure 1. The positions were indicated by shoreward distance from a reference point near the shoreline. As hydraulic factors, offshore wave energy flux and daily mean sea level were obtained from measurements near the coast.

\section{METHODS}

Using FFT method, we calculated the cross-spectrum between the contour changes for each reference level and the hydraulic conditions. The reference levels of the contour positions were defined every $5 \mathrm{~cm}$ from $-1.0 \mathrm{~m}$. In this study, we focused 1-year cyclic components.

\section{RESULTS AND CONCLUSION}

The power spectra for 1-year cyclic component of contour change reached its maximum at the contour of $-0.1 \mathrm{~m}$
(Figure 2). The relatively big amplitudes of the contour changes from $-0.8 \mathrm{~m}$ to $0.8 \mathrm{~m}$ were due to strong sediment transport caused by abrupt wave energy dissipation nearer to the shoreline. The peak of negative contour changes were 72 days faster than the peak of the offshore wave energy fluxes on average and were 36 days behind the peak of the sea levels (Figure 2). The beach in the swash zone was eroded the most at the time with relatively high in both the offshore wave energy flux and sea level. Because the phase relation was set with an emphasis on the sea level, the sea level was more influential on the contour changes than the offshore wave energy flux. The phase differences with entire reference levels were almost constant, suggesting that the eroded sediment was uniformly transported offshore from swash zone.

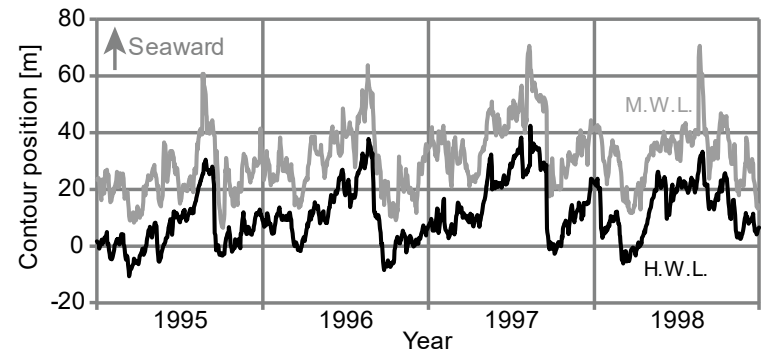

Figure 1 - Time series of M.W.L. and H.W.L. contour position at the Hasaki coast from 1995 to 1998.
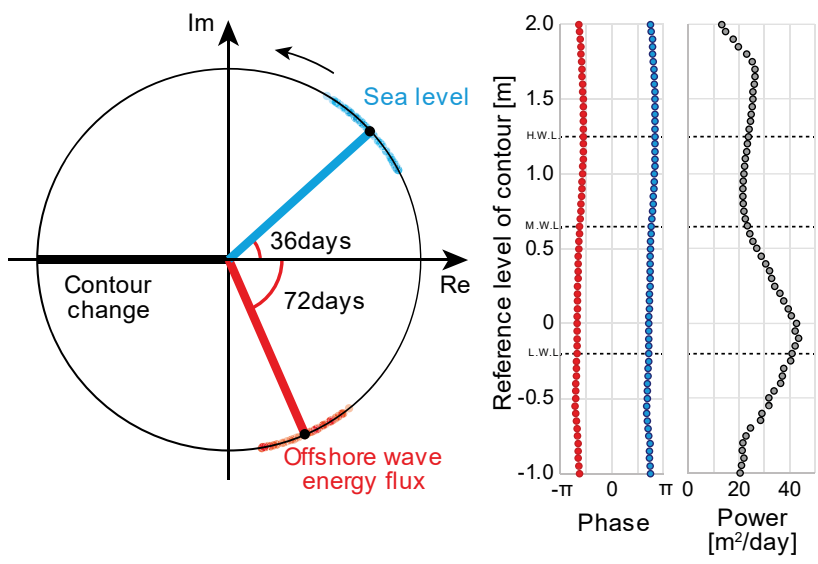

Figure 2 - Phase differences between contour changes and offshore wave energy fluxes (red) or sea levels (blue) for 1year cyclic component. Amplitudes in complex plane (left panel) were normalized. The power spectrum densities of contours were shown in right panel (grey).

\section{REFERENCES}

Bruun, P. (1962): Sea level rise as a cause of shoreline erosion, Journal of the Waterways and Harbors Division, 
Proc. ASCE, Vol. 88, WW1, pp. 117-130.

Barnard, P. L., Hoover, D., Hubbard, D. M., Snyder, A., Ludka, B. C., Allan, J., Kaminsky, G. M., Ruggiero, P., Gallien, T. W., Gabel, L., McCandless, D., Weiner, H. M., Cohn, N., Anderson, D. L. and Serafin, K. A. (2017): Extreme oceanographic forcing and coastal response due to the 2015-2016 El Niño, Nature Communications, 8, 14365. 